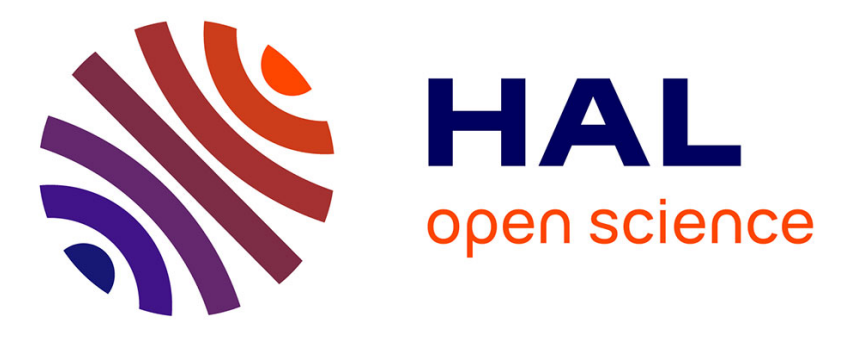

\title{
Mechanical and thermal behaviour of bamboo flour-reinforced XLPE composites
}

\author{
Geoffrey Haddou, Jany Dandurand, Eric Dantras, Huynh Maiduc, Hoang \\ Thai, Nguyen Vu Giang, Tran Huu Trung, Philippe Ponteins, Colette \\ Lacabanne
}

\section{To cite this version:}

Geoffrey Haddou, Jany Dandurand, Eric Dantras, Huynh Maiduc, Hoang Thai, et al.. Mechanical and thermal behaviour of bamboo flour-reinforced XLPE composites. Journal of Thermal Analysis and Calorimetry, 2016, 124 (2), pp.701-708. 10.1007/s10973-015-5176-x . hal-01486588

\section{HAL Id: hal-01486588 \\ https://hal.science/hal-01486588}

Submitted on 10 Mar 2017

HAL is a multi-disciplinary open access archive for the deposit and dissemination of scientific research documents, whether they are published or not. The documents may come from teaching and research institutions in France or abroad, or from public or private research centers.
L'archive ouverte pluridisciplinaire HAL, est destinée au dépôt et à la diffusion de documents scientifiques de niveau recherche, publiés ou non, émanant des établissements d'enseignement et de recherche français ou étrangers, des laboratoires publics ou privés. 


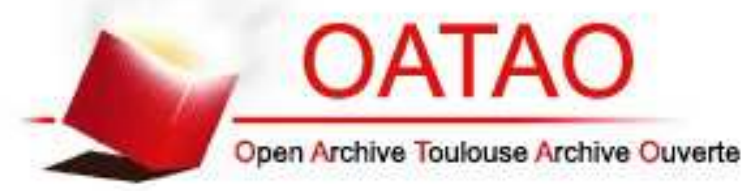

\section{Open Archive TOULOUSE Archive Ouverte (OATAO)}

OATAO is an open access repository that collects the work of Toulouse researchers and makes it freely available over the web where possible.

This is an author-deposited version published in : http://oatao.univ-toulouse.fr/ Eprints ID : 16731

To link to this article : DOI:10.1007/s10973-015-5176-x

URL : http://dx.doi.org/10.1007/s10973-015-5176-x

To cite this version : Haddou, Geoffrey and Dandurand, Jany and Dantras, Eric and Maiduc, Huynh and Thai, Hoang and Giang, Nguyen Vu and Trung, Tran Huu and Ponteins, Philippe and Lacabanne, Colette Mechanical and thermal behaviour of bamboo flour-reinforced XLPE composites. (2016) Journal of Thermal Analysis and Calorimetry, vol. $124\left(\mathrm{n}^{\circ} 2\right)$. pp. 701-708. ISSN 13886150

Any correspondence concerning this service should be sent to the repository administrator: staff-oatao@ listes-diff.inp-toulouse.fr 


\title{
Mechanical and thermal behaviour of bamboo flour-reinforced XLPE composites
}

\author{
Geoffrey Haddou ${ }^{1,2} \cdot$ Jany Dandurand ${ }^{1} \cdot$ Eric Dantras $^{1} \cdot$ Huynh Maiduc $^{3} \cdot$ \\ Hoang Thai ${ }^{3}$ Nguyen Vu Giang ${ }^{3}$ Tran Huu Trung ${ }^{3} \cdot$ Philippe Ponteins $^{2}$. \\ Colette Lacabanne ${ }^{1}$
}

\begin{abstract}
In the present work, the influence of natural fillers (bamboo flour/BF) on crosslinked polyethylene (XLPE) has been discussed. The main difficulty for the preparation of the composites is to establish adhesion between hydrophilic natural fillers and hydrophobic matrix. Consequently, coupling agent (CA) as silane must be added to promote interface. In this work, different amounts of tetraethyl orthosilicate (TEOS) were used as coupling agent and SEM images allow us to control the quality of the interface. Differential scanning calorimetry (DSC) shows that the XLPE crystallinity is unmodified upon the introduction of BF. The absence of transcrystallinity is important for preserving the ductility of composites. The dynamic mechanical analyses (DMA) highlight an optimum of shear modulus for a TEOS content of 5 mass $\%$ (CA5). Above this amount, the mechanical properties are reduced. These results were confirmed by the SEM observations which highlighted the decrease in the interface between the XLPE and BF. Furthermore, neither the introduction of $\mathrm{BF}$ nor the treatment with TEOS exerts an influence on the relaxation temperature: there is no plasticization. The combination of DSC/DMA allows us to show that higher viscoelasticity favouring impact strength is observed in XLPE/BF CA5 composites.
\end{abstract}

Eric Dantras

eric.dantras@univ-tlse3.fr

1 Institut Carnot CIRIMAT, Université Paul Sabatier, 31062 Toulouse Cedex 09, France

2 Assystem Toulouse, 13 rue Marie Louise Dissard, 31300 Toulouse Cedex 09, France

3 Institute for Tropical Technology, Vietnamese Academy of Science and Technology, 18 Hoang Quoc Viet Road, Cau Giay District, Hanoi, Vietnam
Keywords Dynamic mechanical analysis - DSC . Bamboo fibre $\cdot$ Compatibility $\cdot$ XLPE $\cdot$ Coupling agent

\section{Introduction}

Polymer composites reinforced with natural fillers like wood fibre or flour have acquired general popularity over the two last decades [1-4]. These environmentally friendly composites [5-7] have many remarkable properties in comparison with conventional composites using glass fibres and mineral fillers because of their low density and low cost. Often, compatibilizers between natural filler and polymeric matrix optimize the mechanical properties [8]. Consequently, wood polymer composites are used in many applications such as lumber, decking, railing, window profiles, door frames, furniture and pallets $[9,10]$. However, the use of wood to make such composites might have consequences on the exploitation and protection of forest even in the case of fast-growing species [11]. Bamboo is abundantly available in many countries. The total bamboo forest area in the world has reached 22 million hectares. Moreover, bamboo is one of the fastest renewable plants with a maturity cycle of 3-4 years. Bamboo possesses excellent mechanical properties in comparison with its mass due to its hierarchical structures [12]. With such advantages, bamboo fillers promise to become one of the best natural reinforcement in polymeric composites [13-20]. Their use can help to reduce the demand for wood flour and environmental impacts associated with wood fibre harvesting.

Composites based on bamboo filler and polymer matrix exhibit some disadvantages, like poor adhesion between matrix and filler that easily absorbed moisture. Indeed, the main components of bamboo, cellulose and hemicellulose, possess a strong hydrophilic character. Consequently, 
hydrophobic properties of the matrix are required: polyolefins such as high-density polyethylene (HDPE) are satisfactory. Then, compatibility between the filler and the matrix is considered as the key to enhance properties of this composite [21, 22]. One route is to use copolymers as coupling agent $[23,24]$. Recent reports on the filler-reinforced composites show that hybrid fillers (combining two or more different types of fillers) have been mainly used. Some studies have explored the effect of mineral filler and lignocellulosic fibres on mechanical properties, thermal stability and weathering resistance [25, 26]. HDPE/bamboo composites with different nanoclays and maleated polyethylene (MAPE) contents were fabricated by melt compounding. The X-ray diffraction (XRD) data showed that the clay was exfoliated only when $1 \%$ clay was added to pure HDPE. For the HDPE/BF composites, tensile strength, bending modulus and strength were improved with the use of MAPE; however, the use of the clay in the system led to reduced mechanical properties. Another method is the modification of the bamboo fibre surface by using suitable surfactants as coupling agents [13]. Li et al. [27] reported the acetylation of Chinese bamboo flour that was chemically modified with acetic anhydride by using trichloroacetic acid as an activation agent. Several studies reported on hydrophobic modifications of bamboo flour [28]. A specific interest was devoted to silane coupling [29-32] that significantly improve adhesion in composites. Alkali treatment affects the swelling of cellulose fibres in converting cellulose structure in a thermodynamically more stable one. Subsequent chemical modification with silane for alkalitreated wood fibres would increase adhesion with polymer matrix in wood polymer composites. The use of silanes transforms hydrophilic surface of wood fibres into hydrophobic surface by silanol formation and bonding between siloxane and fibres [33]. Lee et al. [34] showed the effects of chemical modification (silane coupling) and filler loading on the fundamental properties of the bamboo fibres filled polypropylene (PP). The addition of aminopropyltrimethoxysilane (AS) and tetramethoxy orthosilicate (TMOS) after the alkali pretreatment of bamboo fibres improved adhesion between the bamboo fibres and PP matrix. Consequently, the resultant composites had improved tensile, flexural and impact strength.

Tabari et al. [35] have added $\mathrm{SiO}_{2}$ nanoparticles during mixing of wood flour and PP using the injection moulding process. The results showed that the bending strength of the material significantly increases in comparison with original material without $\mathrm{SiO}_{2}$ nanoparticles. However, mineral nanofillers used in the wood polymer composite also showed a few drawbacks like the agglomeration of nanofillers in the matrix and no chemical interaction with other components.
In order to overcome these problems in this study, the Vietnamese bamboo flour (BF) was modified by tetraethyl orthosilicate (TEOS) in ethanol solution to form in situ $\mathrm{SiO}_{2}$ nanoparticles on the BF surface. The chemical bonds were established through condensation reaction of hydroxyl groups between the $\mathrm{BF}$ and $\mathrm{SiO}_{2}$ nanoparticles. Therefore, $\mathrm{SiO}_{2}$ could show a fine scattering on the BF and played an important role in improving the mechanical properties of HDPE matrix. In addition, dicumyl peroxide (DCP) played the role of the crosslinking agent of the matrix. Scanning electron microscopy allowed us to observe the bamboo flour/XLPE interface. After checking that the physical structure of the matrix was not modified, the performances of the composite were investigated under shear strain.

\section{Experimental}

\section{Materials}

\section{Polymer matrix}

High-density polyethylene (HDPE), with density of $0.96 \mathrm{~g} \mathrm{~cm}^{-3}$, was purchased from LG Chemical Company (Korea). During processing, HDPE was crosslinked by dicumyl peroxide (DCP) (98\%) provided by Merck Company (Germany). Crosslinked HDPE was referred as XLPE.

\section{Bamboo flour}

The BF (moisture lower than $12 \%$ ) of Dendrocalamus barbatus (North Vietnam) was provided by VNDD Ltd. (Vietnam). The BF was ground and passed through 100-mesh sieve to select the final grains that were dried in an oven for $5 \mathrm{~h}$ at $100{ }^{\circ} \mathrm{C}$ to totally remove humidity. Tetraethyl orthosilicate (TEOS) with $0.934 \mathrm{~g} \mathrm{~cm}^{-3}$ was purchased from Daejung Company (Korea). The BF was added into the ethanol solution containing TEOS with various weight ratios: $m_{\mathrm{TEOS}} / m_{\mathrm{BF}}=5$ and $10 \mathrm{mass} \%$, in which ammonia solution was used to adjust the $\mathrm{pH}$ of the mixture between 8 and 9. Ethanol solution $\left(\mathrm{C}_{2} \mathrm{H}_{5} \mathrm{OH}\right)(99.7 \%)$ and ammonia solution $\left(\mathrm{NH}_{4} \mathrm{OH}\right)(25 \%)$ are commercial products of Duc Giang Chemical Company (Vietnam). After 30 min, distilled water was dropped into above mixture and maintained at a temperature of $50{ }^{\circ} \mathrm{C}$ with magnetic stirring for $2 \mathrm{~h}$. After that, the BF was filtered and washed by alcohol under low pressure to remove the residual TEOS. Finally, the BF was dried in a vacuum oven at $80^{\circ} \mathrm{C}$ for $8 \mathrm{~h}$.

\section{Processing of composites}

Treated or untreated BF (with 5 and 10 mass $\%$ of TEOS) was mixed with HDPE (containing $0.1 \%$ DCP in 
comparison with HDPE mass) at ratio $m_{\mathrm{HDPE}} / m_{\mathrm{BF}}=60$ / 40 by melt-mixing method in a Haake intermixer at $185^{\circ} \mathrm{C}$ for $5 \mathrm{~min}$; the rotor speed was $80 \mathrm{rpm}$. Then, the above composites were pressed into thin sheets form using Toyo Seiki Press machine (Japan). They were subjected for $2 \mathrm{~min}$ at a pressure of $5 \mathrm{MPa}$ at a temperature of $190{ }^{\circ} \mathrm{C}$. Then, the final samples were cooled down and kept at room temperature at least 1 day before further characterization and analysis. In this study, the crosslinked matrix (using DCP in HDPE) is referred as XLPE. The series of XLPE/bamboo flour composites were investigated: a BF content of 40 mass\% corresponds to an optimum of the final mechanical properties according to the literature [35]. The sample formulation is reported in Table 1: CA0 designates composites with untreated bamboo flour, and CA5 and CA10 correspond to composites containing bamboo flour, respectively, treated by 5 and $10 \%$ of coupling agent (CA).

\section{Methods}

\section{SEM}

Scanning electron microscopy (SEM) was used for the observation of cryo-fractured surfaces obtained by breaking XLPE/BF composites frozen in liquid nitrogen. The surfaces were observed by using a JSM 6700F (JEOL, Japan) and equipped with field emission gun, at a voltage of $5 \mathrm{kV}$.

\section{Differential scanning calorimetry}

Differential scanning calorimetry (DSC) was performed on a Diamond DSC (PerkinElmer, USA). The samples between 10 and $15 \mathrm{mg}$ were placed in aluminium pans. The crystallinity was evaluated from 20 to $150{ }^{\circ} \mathrm{C}$ at $20{ }^{\circ} \mathrm{C} \mathrm{min}{ }^{-1}$.

\section{Dynamic mechanical analysis}

Dynamic mechanical analyses (DMA) were performed using an ARES set-up (Rheometric Scientific, USA). The measurements were taken from -140 to $100{ }^{\circ} \mathrm{C}$, with a

Table 1 Mass ratio of XLPE, BF and TEOS for the composites

\begin{tabular}{lccl}
\hline Samples & XLPE/mass\% & $\mathrm{BF} /$ mass\% & $\begin{array}{l}\text { TEOS/BF } \\
\text { ratio/mass\% }\end{array}$ \\
\hline XLPE (reference) & 100 & 0 & - \\
CA0 & 60 & 40 & 0 \\
CA5 & 60 & 40 & 5 \\
CA10 & 60 & 40 & 10 \\
\hline
\end{tabular}

heating rate of $3{ }^{\circ} \mathrm{C} \mathrm{min}^{-1}$, under nitrogen flow, at a frequency of $1 \mathrm{rad} \mathrm{s}^{-1}$, with a dynamic strain of $0.1 \%$.

\section{Results and discussion}

\section{Morphology analysis}

Figure 1 shows the morphology of composites via SEM images of cryo cuts. In Fig. 1a, a void between XLPE and BF can be observed. This discontinuity means that the compatibility between the matrix and the blends is quite poor. In Fig. 1b, for the composite CA5, the gap at the interface disappears. This image indicates an improvement in the compatibility between XLPE and BF due to the addition of 5 mass $\%$ TEOS during composite processing. In the case of the composite CA10, it is clear that 10 mass\% TEOS decreases the adhesion between XLPE and BF.

Wang et al. [36] create coupling between wood flour and PP using maleic anhydride-grafted PP (MAPP) or silane as coupling agents. In the case of the use of silane, they highlighted that there is a critical ratio which is equal to 1.5 mass $\%$ for 50 mass $\%$ in wood fibres. This ratio is inferior to ours. For future study, it will be necessary to determine more precisely the critical ratio of TEOS in XLPE/BF composites. Above this ratio, the properties of the composites are unchanged or even damaged. $\mathrm{Wu}$ et al. [24] proposed several hypotheses: by-product formation, increase in the concentration of unreacted coupling agent and interference between interactions. They also determine the limits in coupling agent proportions from 2 to 8 mass $\%$. Our limit ratio is consistent with these values.

\section{Physical structure}

Melting peaks of XLPE and 3 samples of composite CA0 are shown in Fig. 2. The degree of crystallinity for XLPE was calculated using the following equation:

$\chi_{\mathrm{c}}=\frac{\Delta H_{\mathrm{m}}}{\Delta H_{\infty}} \times 100 \%$

where $\chi_{\mathrm{c}}$ is the crystallinity ratio, $\Delta H_{\mathrm{m}}$ is the measured melting enthalpy, and $\Delta H_{\infty}$ is the theoretical melting enthalpy of $100 \%$ crystalline polyethylene taken here as $290 \mathrm{~J} \mathrm{~g}^{-1}$ [37].

The thermal characteristics for each sample are indexed in Table 2.

The melting temperature of XLPE is $136{ }^{\circ} \mathrm{C}$ with a high and sharp peak. For CA0 composites, the melting temperature increases and reaches $140{ }^{\circ} \mathrm{C}$. The melting of composites is higher than for XLPE. This shift can be explained by the following considerations: the presence of $\mathrm{BF}$ increases the thermal inertia because BF mainly composed 
Fig. 1 SEM images of a CA0, b CA5 and c CA10 composites

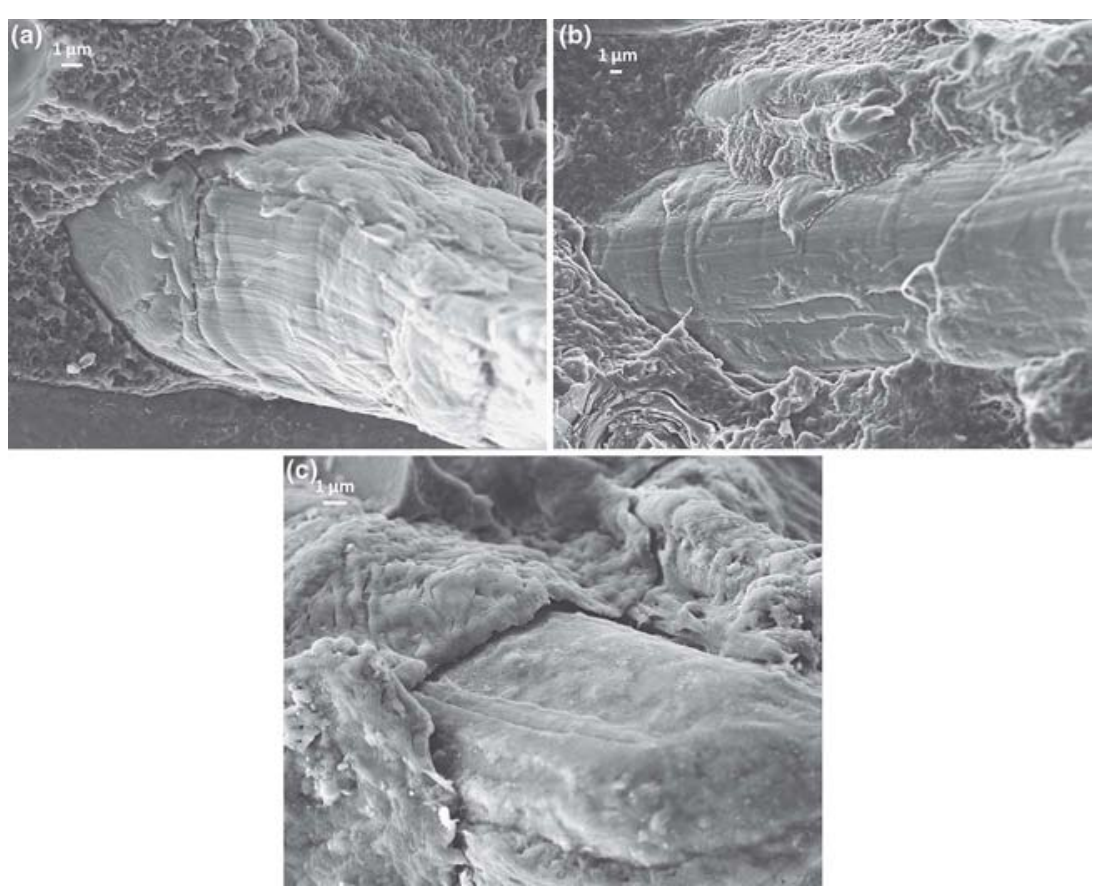

value of crystallinity for the composites is $62 \%$ which is close to the value of bulk XLPE: $66 \%$. It shows that BF has no significant influence on the crystallinity of XLPE.

Earlier studies involved treatment that contains polymeric sequences compatible with the matrix. In such conditions, the introduction of natural fillers may have an influence on the matrix's crystallinity [38]. Bouzouita et al. [39] showed the crystallinity of PP increased by $11 \%$ when hemp fibres were introduced. This evolution was associated with the presence of transcrystallization at the interface between PP and fibres. Joseph et al. [40] had similar results using short sisal fibre-reinforced PP. The variation of crystallinity is dependent upon the treatment of the filler. Analogous data have been reported by Kumar et al. [41] for short bamboo fibres/LLDPE composites. It should also be noted that Suñol and Saurina [42] observed that the crystallinity of wood fibre/HDPE composites is independent from its environment. Along these lines, it is not surprising that in our composites, there is no modification of the crystallinity.

\section{Mechanical relaxation modes}

Matrix

In order to indentify the role of the filler on the dynamic mechanical properties of XLPE/BF composites, the relaxation of XLPE matrix was first examined. Storage modulus $G^{\prime}$ and loss modulus $G^{\prime \prime}$ of HDPE and XLPE are illustrated, respectively, in Figs. 3 and 4. composites

\begin{tabular}{llll}
\hline Samples & $T_{\mathrm{m}}{ }^{\circ} \mathrm{C}$ & $\Delta H_{\mathrm{m}} / \mathrm{J} \mathrm{g}^{-1}$ & $\chi_{\mathrm{c}}{ } \%$ \\
\hline XLPE (reference) & 136 & 192 & 66 \\
CA0 1 & 141 & 177 & 61 \\
CA0 2 & 138 & 183 & 63 \\
CA0 3 & 140 & 182 & 62 \\
Average $^{\mathrm{a}}$ & $140(1)$ & $181(3)$ & $62(1)$ \\
\hline
\end{tabular}

\footnotetext{
of cellulose is a better thermal insulator than XLPE.
Moreover, the used heating rate is quite high so that the
composites are not completely at equilibrium. The mean

of cellulose is a better thermal insulator than XLPE.
Moreover, the used heating rate is quite high so that the
composites are not completely at equilibrium. The mean

${ }^{a}$ Numbers between brackets are the standard deviation
} 


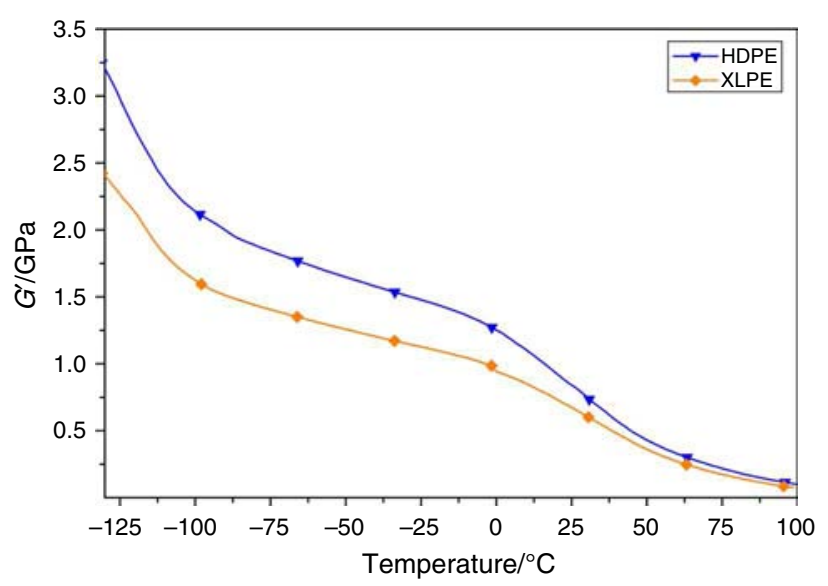

Fig. 3 Shear storage modulus $G^{\prime}$ of HDPE and XLPE

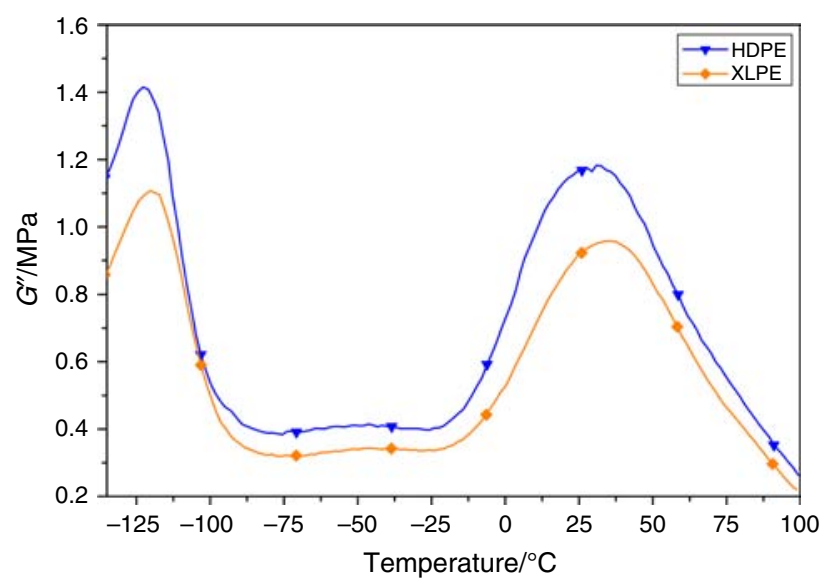

Fig. 4 Shear loss modulus $G^{\prime \prime}$ of HDPE and XLPE

Figure 3 highlights higher value of the conservative modulus in HDPE compared with XLPE: this observation is consistent with the fact that crosslinking with DCP restricts molecular mobility [43, 44]. Khonakdar et al. [43] also showed a decrease of $23 \%$ of the bending properties due to crosslinking. In this study, the glassy plateau of XLPE is $25 \%$ lower than the HDPE one i.e. in good agreement with previous findings. There is a decrease in the $G^{\prime}$ values with increasing temperature due to the relaxation of the mobile sequences between entanglements. The step located around $30{ }^{\circ} \mathrm{C}$ corresponds to the relaxation of sequences in the amorphous-crystalline interphase: this mode is generally designated as $\alpha_{\mathrm{c}}$. Note that the rubbery plateau has the same value for both XLPE and HDPE. Khonakdar et al. [43] reported a different behaviour: the rubbery modulus of XLPE decreases like the glassy modulus due to a decrease in crystallinity. Figure 4 shows the $\gamma$ relaxation mode at $-120{ }^{\circ} \mathrm{C}$ which is associated with the anelastic relaxation of polyethylene sequences of amorphous phases free of defects of both HDPE and XLPE. This intrinsic relaxation is associated with the glass transition of polyethylene. Around $-40{ }^{\circ} \mathrm{C}$, a small peak, generally designated as $\beta$, reflects the mobility of sequences of the amorphous domains containing chemical defects such as crosslinks. At $40{ }^{\circ} \mathrm{C}$, the $\alpha_{c}$ relaxation is associated with the reorientation of defects at the boundary of the crystalline phase of the matrix [45, 46]. It is interesting to note that the temperatures of all relaxations are independent from the chain architecture. This result is consistent with previous findings on a systematic study of polyethylene with different short-chain branching [47].

\section{Influence of bamboo flour on the relaxation modes of composites}

In this section, the influence of the introduction of BF with various percentages of coupling agent was studied by DMA.

Figure 5 presents the storage modulus $G^{\prime}$ of XLPE and XLPE/BF composites. Even for CA0, the composite has a higher storage modulus than for XLPE. Liu et al. [48] have also observed an improvement in the mechanical behaviour by introducing untreated BF in a HDPE matrix. The increase in the modulus of XLPE upon the introduction of untreated $\mathrm{BF}$ may be due to Vander Waals interactions between BF and the matrix. When BF is treated with 5 mass $\%$ of TEOS, the glassy modulus is improved, while the rubbery modulus remains analogous with the one of CA0. Above $40{ }^{\circ} \mathrm{C}$, the influence of TEOS is negligible: it indicates that the introduction of $\mathrm{BF}$ untreated or treated does not restrict the mobility of XLPE chains in the rubbery state. In the case of CA10, the glassy plateau is lower than CA5. It might indicate that remaining TEOS forms nodules in the matrix. DMA allows us to determine the critical content of coupling agent. These results are consistent with structural observations from SEM. The molecular origin of the decrease in the conservative modulus above $5 \% \mathrm{CA}$ might be by-products formation and an increase in unreacted coupling agent. Consequently, the increase in $\mathrm{CA}$ acts against the improvement in mechanical properties.

The dependence of $G^{\prime \prime}$ on temperature for XLPE and the XLPE/BF composites is shown in Fig. 6. Then, the $\gamma, \beta$ and $\alpha_{c}$ relaxations are resolved. The temperatures of the peaks are not significantly modified by the introduction of BF. In other words, there is no plasticization due to the BF introduction. It is important to mention here that 5 mass $\%$ of TEOS appears as optimum since, for 10 mass $\%$ of TEOS, the magnitude of the $\gamma$ mode decreases. Consequently, the impact strength decreases.

The $\gamma$ relaxation located at $-120{ }^{\circ} \mathrm{C}$ corresponds to the viscoelastic energy loss associated with the glass transition of the amorphous phase free from chemical defects. A broadening of the $\gamma$ peak appears around $-80{ }^{\circ} \mathrm{C}$. This broadening increases by treating $\mathrm{BF}$ with 5 mass $\%$ of 


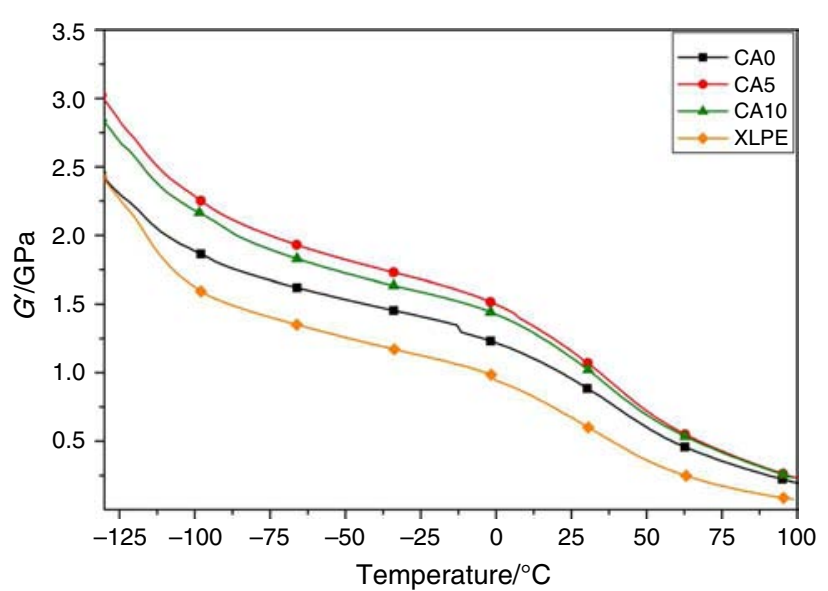

Fig. 5 Storage modulus $G^{\prime}$ for XLPE and XLPE/BF composites

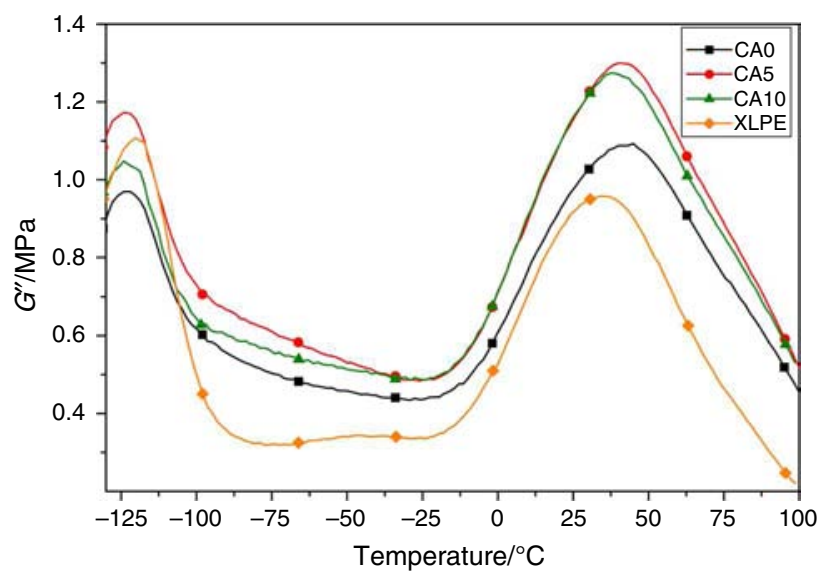

Fig. 6 Loss modulus $G^{\prime \prime}$ for XLPE and XLPE/BF composites

TEOS: it indicates that this phenomenon is dependent upon the presence of bamboo flour within the amorphous XLPE phase. The amorphous phase containing BF is segregated. A bump is observed at $-40{ }^{\circ} \mathrm{C}$ in XLPE. According to previous data on polyethylene with different short-chain branching, this event has been assigned to the mobility in amorphous regions of XLPE with chemical defects. The $\alpha_{c}$ mode, situated around $40{ }^{\circ} \mathrm{C}$, has been associated with the mobility in the interfacial regions at the periphery of crystallites. Its magnitude is higher in all XLPE/BF composites showing that there is also a contribution of the mobility at the polymer/BF interface.

\section{Conclusions}

The evolution of thermal and mechanical properties of XLPE/bamboo flour (BF) composites, observed by a combination of DSC/DMA analyses, is discussed using as reference bulk XLPE. SEM observations show the existence of a continuity of matter at the interface for percentages of TEOS (CA) close to 5 mass\%. For 10 mass \% of TEOS, a void is observed between XLPE and BF. The study of the physical structure performed by DSC shows the crystallinity was unmodified upon the introduction of fillers. The absence of transcrystallinity is important for preserving the ductility of composites.

DMA analyses show that the introduction of $\mathrm{BF}$ improves the glassy modulus owing to Vander Waals interactions. This effect is amplified in XLPE/BF due to polar interactions created by the coupling agent. The amount of 5 mass $\%$ of CA corresponds to an optimum of viscoelasticity. Above this critical content, the storage modulus decreases due to a bad interphase as observed by SEM. The anelastic relaxation modes of XLPE/BF composites are located at the same temperatures than for the XLPE matrix showing the absence of plasticization independently from the coupling agent content.

The $\gamma$ relaxation located at $-120{ }^{\circ} \mathrm{C}$ corresponds to the viscoelastic energy loss associated with the glass transition of the amorphous phase free from chemical defects. It exhibits, around $-80{ }^{\circ} \mathrm{C}$, a shoulder characteristic of the presence of bamboo flour within the amorphous XLPE phase: it indicates a segregation of the amorphous phase containing BF. The $\alpha_{\mathrm{c}}$ mode, situated around $40{ }^{\circ} \mathrm{C}$, has been associated with the mobility in the interfacial regions. In XLPE, this molecular mobility is located at the periphery of crystallites. Since its magnitude of the $\alpha_{c}$ mode is higher in all XLPE/BF composites, the mobility at the periphery of $\mathrm{BF}$ is also involved.

Finally, combined DSC/DMA analyses allow us to identify the molecular origin of the anelastic properties of $\mathrm{XLPE} / \mathrm{BF}$ composites as a function of CA content.

Acknowledgements The work was done in the framework of the International Associated Laboratory "FUNCTIONAL COMPOSITE MATERIALS" (FOCOMAT) supported by CNRS and VAST. The financial support of Assystem and ANRT is greatly acknowledged.

\section{References}

1. Huda MS, Drzal LT, Misra M, Mohanty AK. Wood-fiber-reinforced poly(lactic acid) composites: evaluation of the physicomechanical and morphological properties. J Appl Polym Sci. 2006;102:4856-69.

2. Li X, Tabil LG, Panigrahi S. Chemical treatments of natural fiber for use in natural fiber-reinforced composites: a review. J Polym Environ. 2007;15:25-33.

3. Bogoeva-Gaceva G, Avella M, Malinconico M, Buzarovska A, Grozdanov A, Gentile G, et al. Natural fiber eco-composites. Polym Compos. 2007;28:98-107.

4. Schlechter M. Plastic wood: technologies, market. Norwalk: Business Communications Co.; 2004.

5. Shalwan A, Yousif BF. In state of art: mechanical and tribological behaviour of polymeric composites based on natural fibres. Mater Des. 2012;48:14-24. 
6. Zhang X, Wu X, Haryono H, Xia K. Natural polymer biocomposites produced from processing raw wood flour by severe shear deformation. Carbohydr Polym. 2014;113:46-52.

7. Ou R, Wang Q, Wolcott MP, Sui S, Xie Y, Song Y. Effects of chemical modification of wood flour on the rheological properties of high-density polyethylene blends. J Appl Polym Sci. 2014;131: $1-7$.

8. Hong $\mathrm{H}$, Liao $\mathrm{H}$, Zhang $\mathrm{H}$, He H, Liu T, Jia D. Significant improvement in performance of recycled polyethylene/wood flour composites by synergistic compatibilization at multi-scale interfaces. Compos Part A Appl Sci Manuf. 2014;64:90-8.

9. Burgueño R, Quagliata MJ, Mehta GM, Mohanty AK, Misra M, Drzal LT. Sustainable cellular biocomposites from natural fibers and unsaturated polyester resin for housing panel applications. J Polym Environ. 2005;13:139-49.

10. Saheb DN, Jog JP. Natural fiber polymer composites: a review. Adv Polym Technol. 1999;18:351-63.

11. Catto AL, Stefani BV, Ribeiro VF, Marlene R, Santana C. Influence of coupling agent in compatibility of post-consumer HDPE in thermoplastic composites reinforced with eucalyptus fiber. Mater Res. 2014;17:203-9.

12. Tan T, Rahbar N, Allameh SM, Kwofie S, Dissmore D, Ghavami $\mathrm{K}$, et al. Mechanical properties of functionally graded hierarchical bamboo structures. Acta Biomater Acta Mater Inc. 2011;7: 3796-803.

13. Chen Q, Mao X, Xue H, Deng Y, Lin J. Preparation and characterization of bamboo fiber-graft-lauryl methacrylate and its composites with polypropylene. J Appl Polym Sci. 2013;130:2377-82.

14. Han G, Lei Y, Wu Q, Kojima Y, Suzuki S. Bamboo-fiber filled high density polyethylene composites: effect of coupling treatment and nanoclay. J Polym Environ. 2008;16:123-30.

15. Abdul Khalil HPS, Bhat IUH, Jawaid M, Zaidon A, Hermawan D, Hadi YS. Bamboo fibre reinforced biocomposites: a review. Mater Des. 2012;42:353-68.

16. Delgado PS, Lana SLB, Ayres E, Patrício POS, Oréfice RL. The potential of bamboo in the design of polymer composites. Mater Res. 2012;15:639-44.

17. Yu Y, Wang H, Lu F, Tian G, Lin J. Bamboo fibers for composite applications: a mechanical and morphological investigation. J Mater Sci. 2013;49:2559-66.

18. Adhikari R, Bhandari NL, Causin V, Le HH, Radusch H-J, Michler $\mathrm{GH}$, et al. Study of morphology, mechanical properties, and thermal behavior of green aliphatic-aromatic copolyester/bamboo flour composites. Polym Eng Sci. 2012;52:2296-303.

19. $\mathrm{Xu} \mathrm{Y,} \mathrm{Lee} \mathrm{SY,} \mathrm{Wu} \mathrm{Q.} \mathrm{Creep} \mathrm{analysis} \mathrm{of} \mathrm{bamboo} \mathrm{high-density}$ polyethylene composites: effect of interfacial treatment and fiber loading level. Polym Compos. 2011;32:692-9.

20. Nourbakhsh A, Ashori A, Ziaei Tabari H, Rezaei F. Mechanical and thermo-chemical properties of wood-flour/polypropylene blends. Polym Bull. 2010;65:691-700.

21. Wang YN, Weng YX, Wang L. Characterization of interfacial compatibility of polylactic acid and bamboo flour (PLA/BF) in biocomposites. Polym Test. 2014;36:119-25.

22. Kim H-S, Kim S, Kim H-J, Yang H-S. Thermal properties of bioflour-filled polyolefin composites with different compatibilizing agent type and content. Thermochim Acta. 2006;451:181-8.

23. Lu JZ, Wu Q, Negulescu II. Wood-fiber/high-density-polyethylene composites: coupling agent performance. J Appl Polym Sci. 2005;96:93-102.

24. Wu Q, Lu JZ, Mcnabb HS Jr. Chemical coupling in wood fiber and polymer composites: a review of coupling agents and treatments. Wood Fiber Sci. 2000;32:88-104.

25. Nourbakhsh A, Baghlani FF, Ashori A. Nano- $\mathrm{SiO}_{2}$ filled rice husk/polypropylene composites: physico-mechanical properties. Ind Crops Prod. 2011;33:183-7.
26. Kim JY, Peck JH, Hwang SH, Hong J, Hong SC, Huh W, et al. Preparation and mechanical properties of poly(vinyl chloride)/ bamboo flour composites with a novel block copolymer as a coupling agent. J Appl Polym Sci. 2008;108:2654-9.

27. Li XF, Chen QH, Lin JH, Zhuo DX, Wu XL. Acetylation of Chinese bamboo flour and thermoplasticity. J For Res. 2008;19:69-71.

28. Yu F, Yang W, Song J, Wu Q, Chen L. Investigation on hydrophobic modification of bamboo flour surface by means of atom transfer radical polymerization method. Wood Sci Technol. 2014;48:289-99.

29. Van de Weyenberg I, Chi Truong T, Vangrimde B, Verpoest I. Improving the properties of UD flax fibre reinforced composites by applying an alkaline fibre treatment. Compos Part A Appl Sci Manuf. 2006;37:1368-76.

30. Coutinho MBF, Costa THS, Carvalho DL, Gorelova MM, Claudio de Santa Maria L. Thermal behaviour of modified wood fibers. Polym Test. 1998;17:299-310.

31. Pickering KL, Abdalla A, Ji C, McDonald AG, Franich RA. The effect of silane coupling agents on radiata pine fibre for use in thermoplastic matrix composites. Compos Part A Appl Sci Manuf. 2003;34:915-26.

32. Park BD, Wi SG, Lee KH, Singh AP, Yoon TH, Kim YS. X-ray photoelectron spectroscopy of rice husk surface modified with maleated polypropylene and silane. Biomass Bioenergy. 2004;27: 353-63.

33. Xie Y, Hill CAS, Xiao Z, Militz H, Mai C. Silane coupling agents used for natural fiber/polymer composites: a review. Compos Part A Appl Sci Manuf. 2010;41:806-19.

34. Lee S-Y, Chun S-J, Doh G-H, Kang I-A, Lee S, Paik K-H. Influence of chemical modification and filler loading on fundamental properties of bamboo fibers reinforced polypropylene composites. J Compos Mater. 2009;43:1639-57.

35. Tabari HZ, Nourbakhsh A, Ashori A. Effects of nanoclay and coupling agent on the physico-mechanical, morphological, and thermal properties of wood flour/polypropylene composites. Polym Eng Sci. 2011;51:272-7.

36. Wang Y, Cao J, Zhu L, Zhao G. Interfacial compatibility of wood flour/polypropylene composites by stress relaxation method. J Appl Polym Sci. 2012;126:E89-95.

37. Ke QQ, Huang XY, Wei P, Wang GL, Jiang PK. Thermal, mechanical, and dielectric behaviors of crosslinked linear low density polyethylene/polyolefin elastomers blends. J Appl Polym Sci. 2007;104:1920-7.

38. Roumeli E, Terzopoulou Z, Pavlidou E. Effect of maleic anhydride on the mechanical and thermal properties of hemp/highdensity polyethylene green composites. J Therm Anal Calorim. 2015;121:93-105.

39. Bouzouita S, Salvia M, Ben Daly H, Dogui A, Forest E. Effect of fiber treatment on fiber strength and fiber/matrix interface of hemp reinforced polypropylene composites. Adv Mater Res. 2010;112:1-8.

40. Joseph PV, Joseph K, Thomas S, Pillai CKS, Prasad VS, Groeninckx G, et al. The thermal and crystallisation studies of short sisal fibre reinforced polypropylene composites. Compos Part A Appl Sci Manuf. 2003;34:253-66.

41. Kumar S, Choudhary V, Kumar R. Study on the compatibility of unbleached and bleached bamboo-fiber with LLDPE matrix. J Therm Anal Calorim. 2010;102:751-61.

42. Suñol JJ, Saurina J. Thermal analysis of aged HDPE based composites. J Therm Anal Calorim. 2002;70:57-62.

43. Khonakdar HA, Morshedian J, Wagenknecht U, Jafari SH. An investigation of chemical crosslinking effect on properties of high-density polyethylene. Polymer (Guildf). 2003;44: 4301-9. 
44. Khonakdar HA, Wagenknecht U, Jafari SH, Hässler R, Eslami H. Dynamic mechanical properties and morphology of polyethylene/ ethylene vinyl acetate copolymer blends. Adv Polym Technol. 2004;23:307-15.

45. Ward IM. Mechanical properties of solid polymers. 2nd ed. New York: Wiley; 1993.

46. Sha H, Zhang X, Harrison IR. A dynamic mechanical thermal analysis (DMTA) study of polyethylenes. Thermochim Acta. 1991;192:233-42.
47. Ogreten D. Transitions et propriétés mécaniques de films de polyéthylène basse densité linéaire pour ballons stratosphériques ouverts. Toulouse: University Paul Sabatier; 2004.

48. Liu H, Wu Q, Han G, Yao F, Kojima Y, Suzuki S. Compatibilizing and toughening bamboo flour-filled HDPE composites: mechanical properties and morphologies. Compos Part A. 2008;39:1891-900. 